\title{
The RunSmart training program: effect on oxygen consumption and lower extremity biomechanics during running
}

\author{
Jennifer Bogulski', Steven Gonser², Doug Bush³, Raechel Bugner', Lindsay Clark', Lisa Farrell', Kristen Swanson', Michael David Ross ${ }^{1, *}$ \\ 'Daemen College, Amherst, NY, USA \\ Buffalo Rehab Group, Williamsville, NY, USA \\ ${ }^{3}$ Endurance Factor, Ellicottville, NY, USA \\ ${ }^{4}$ Finish Line Physical Therapy, New York, NY, USA
}

As recreational running continues to gain popularity, more individuals are seeking ways to improve running performance. RunSmart is a running intervention program designed to enhance a runner's form. In addition to correcting flaws in a runner's form, RunSmart offers the opportunity for runners to continue a regular regimen while slowly integrating changes in form. The purpose of this case series was twofold: to determine if the RunSmart program coincides with improvements in oxygen consumption $\left(\mathrm{VO}_{2}\right)$, a variable often associated with better running performance times, and to evaluate the RunSmart program in regard to enhancing gait biomechanics. Five recreational runners volunteered to participate in this program. Subjects initially reported to the clinic for an initial submaximal $\mathrm{VO}_{2}$ treadmill test and lower extremity biomechanical analysis. After the initial testing session, each subject attended one session of one-on-one individualized RunSmart instruction per week for 6 weeks. At the first RunSmart session, subjects received a biomechanical analysis to determine their foot strike pattern and areas of muscular weakness and range of motion limitations. Throughout the 6-week run- ning program, participants ran 5 days every week for predetermined times each day; 2 runs every week were designated as interval training runs. Subjects then underwent a follow-up submaximal $\mathrm{VO}_{2}$ treadmill test and lower extremity biomechanical analysis at the end of 6 weeks. Descriptive statistics were used to assess data pertaining to $\mathrm{VO}_{2}$ and biomechanical analysis and compare initial and follow-up testing sessions. Following completion of the RunSmart program, subjects demonstrated improvements in $\mathrm{VO}_{2}$ and also improved several biomechanical factors related to the lower extremity running gait. Based on the results from this case series, the RunSmart training program may have the potential to change a runner's form and improve $\mathrm{VO}_{2}$, thus resulting in improved distance running times. However, this is speculation given the nonexperimental nature of this case series. Future research on this topic should include a greater number of participants in randomized controlled trials on injury prevention and running efficiency.

Keywords: Running, Oxygen consumption, Biomechanics

\section{INTRODUCTION}

As recreational running continues to gain popularity, more individuals are seeking ways to improve running performance. Variables believed to influence performance include gait kinematics, biomechanical factors, and various intervention strategies. Stride length, stride rate, vertical oscillation, arm movement, and range of motion of lower extremity joints all appear to influence performance. However, there is some disagreement among researchers as to which variables are most important for running performance; furthermore, few studies have examined the effect of foot strike patterns on running performance (Anderson, 1996; Cavagna et al., 1964; Cavanagh et al., 1977; Cavanagh and Williams, 1982; Heise and Martin, 1998; Nummela et al., 2007; Tartaruga et al., 2012; Williams and Cavanagh, 1987). Based on the lack of definitive evidence for one specific variable that influence a runner's efficiency, further research is needed to analyze alternative variables, foot strike patterns, and knee extension angle at initial contact.
${ }^{*}$ Corresponding author: Michael David Ross (D) https://orcid.org/0000-0003-1438-9814 Daemen College, 4380 Main Street, Amherst, NY, USA

Tel: +1-7076285950, Fax: +1-7168398537, E-mail: mross@daemen.edu Received: May 31, 2017 / Accepted: August 10, 2017
This is an Open Access article distributed under the terms of the Creative Commons Attribution Non-Commercial License (http://creativecommons.org/licenses/by-nc/4.0/) which permits unrestricted non-commercial use, distribution, and reproduction in any medium, provided the original work is properly cited. 
Additionally, further research is needed to investigate running economy intervention programs, such as RunSmart, that address these biomechanical variables.

RunSmart is a running intervention program designed to enhance a runner's form, particularly foot strike pattern. In addition to a regular running regimen, this program adds individualized drills and strengthening exercises to transition the runner from a rear-foot to mid-foot strike pattern as well as optimize other aspects of a runner's form that influence running performance. Based on video analysis of a runner's form, a physical therapist identifies biomechanical variables hindering a runner's optimal performance and then structures an intervention program designed to address those specific deficiencies. In addition to correcting flaws in a runner's form, RunSmart offers the opportunity for runners to continue a regular regimen while slowly integrating the changes in form addressed by the prescribed exercises. The purpose of this case series was twofold: (a) to determine if the RunSmart program coincides with improvements in oxygen consumption $\left(\mathrm{VO}_{2}\right)$, a variable often associated with better running performance times, and (b) to evaluate the RunSmart program in regard to enhancing gait biomechanics.

\section{MATERIALS AND METHODS}

\section{Subjects}

Subjects were recruited with the use of an informational flyers distributed at the Young Men's Christian Association of Williamsville, NY, Checkers Running Club, and Buffalo Triathlon Club. Inclusion criteria included age between 30 and 40 years, less than 5 years of running experience, weekly running distances of 40 to $56 \mathrm{~km}$, the ability to run $60 \mathrm{~min}$ continuously without stopping, never receiving previous training on proper running form and willingness to complete the 6-week RunSmart training program. Exclusion criteria included a history of spine or lower extremity surgery within the last year, injury/trauma to the spine or lower extremity within the last 6 months, neuromuscular disorders, or systemic disease. Subjects were asked to not complete any other additional training or participate in races during the 6-week program. Informed consent and a health history form were obtained prior to the initial testing. Subjects reported to the clinic for an initial submaximal $\mathrm{VO}_{2}$ treadmill test and lower extremity biomechanical analysis, then they attended a RunSmart session once a week for 6 weeks, and then underwent a follow-up submaximal $\mathrm{VO}_{2}$ treadmill test and lower extremity biomechanical analysis at the end of 6 weeks.

\section{Initial testing}

Data collection for each subject occurred during an initial visit lasting approximately $1 \mathrm{hr}$. Subjects were asked to wear their preferred running shoes for treadmill testing. For testing, reflective tape was affixed to the following locations: left lateral malleolus, midpoint of left lateral knee joint, and left greater trochanter. Markers provided points in which to calculate ankle dorsiflexion angle at initial contact, knee extension angle at initial contact, and maximal hip and knee flexion angles during swing phase during the treadmill test.

During data collection, subjects wore a heart rate monitor that was calibrated with the Med Graphics VO2000, a portable device measuring the gas exchange and energy expenditure at rest and during activity. Med Graphics VO2000 uses a galvanic fuel cell oxygen analyzer and a nondispersive infrared carbon dioxide analyzer as well as a respirator mask to measure oxygen and carbon dioxide volumes used and expelled during running (Wahrlich et al., 2006). Subjects were assessed during 3 stages. Subjects began testing by walking at a fast pace on a treadmill at a $1 \%$ grade for 2 min, which was stage 1 . After 2 min, treadmill speed increased to a slow jog/fast walk pace for another 2 min, which was stage 2 . As testing progressed, subjects reported rate of perceived exertion on a 0 to 10 scale. At 2-min intervals, treadmill speed increased until the subject was running at a pace consistent with a 7 or 8 on the rate of perceived exertion scale. At each speed, interval heart rate, $\mathrm{VO}_{2}$, and carbon dioxide expiration values were collected. Testing progressed until each subject reached threshold (stage 3), which was the point at which $\mathrm{VO}_{2}$ significantly declined and anaerobic respiration occurs. Data collected at this point represented the amount of oxygen consumed at a specific treadmill speed.

While running, subjects were filmed using a video camera at two different speeds: once when they began running and once when they had reached the maximal treadmill speed. Video analysis with Dartfish Software recorded ankle dorsiflexion angle at initial contact, knee extension angle at initial contact, and maximal hip and knee flexion angles during swing phase. Following testing, each participant received an analysis of heart rate levels to be used in a 6-week training schedule. A copy of the specific running schedule is included in the Appendix.

\section{Intervention}

After the initial testing session, each subject attended one session of one-on-one individualized RunSmart instruction per week for 6 weeks. At the first RunSmart session, subjects received a biomechanical analysis to determine their foot strike pattern and 
areas of muscular weakness and range of motion limitations. Following biomechanical analysis in the first session, subjects were instructed to transition gradually to a midfoot strike; a slow, gradual transition was recommended in order to avoid injury. To transition from a heel strike to a midfoot strike, runners were taught to land with the shin in a vertical position; runners practiced this landing pattern while walking and progressively increased their speed so that the pattern was incorporated into their running. Runners were also encouraged to increase the amount of knee flexion and hip flexion during swing to maximize running efficiency. To prevent injury and excessive muscle soreness, runners were sent home with instructions to run in intervals; 3 min with a midfoot strike followed by 1 min of running their "old way." In subsequent sessions, training was focused on muscular weakness and range of motion limitations; runners were also assessed each week to ensure that they were effectively incorporating the new foot strike pattern and run form. Strengthening and range of motion exercises addressed subjects' specific impairments and were individualized to each participant.

Throughout the 6-week running program, participants ran 5 days every week for predetermined times each day; two runs every week were designated as interval training runs. Following initial data collection each subject was provided with 5 heart rate zones specific to their $\mathrm{VO}_{2}$ threshold. Each zone was based on a percentage of a subject's heart rate at $\mathrm{VO}_{2}$ threshold: zone 1 was $<75 \%$, zone 2 was $75 \%$ to $80 \%$, zone 3 was $81 \%$ to $85 \%$, zone 4 was $86 \%$ to $90 \%$, and zone 5 was $91 \%$ to $100 \%$. Each run on the training schedule dictated which heart rate zones subjects needed to attain. Runners tracked heart rate with heart rate monitors during every run to ensure that they remained within the designated heart rate zone. After each run, participants recorded mileage, average heart rate, and pace.

\section{Follow-up testing}

After completion of the 6-week RunSmart program, subjects returned to the initial data collection site for follow-up measurements, which followed the same treadmill protocol as with initial testing and the Med Graphics VO2000 device collected measurements of heart rate, $\mathrm{VO}_{2}$, and carbon dioxide consumption. Video analysis recorded any changes in ankle dorsiflexion angle at initial contact, knee extension angle at initial contact, and maximal hip and knee flexion angles during swing phase following completion of the RunSmart program.
Table 1. Physical characteristics of participants

\begin{tabular}{lclcc}
\hline Subject No. & Age $(\mathrm{yr})$ & Sex & Height $(\mathrm{cm})$ & Weight $(\mathrm{kg})$ \\
\hline 1 & 30 & Male & 152.4 & 90.7 \\
2 & 29 & Female & 172.7 & 68.5 \\
3 & 40 & Male & 172.7 & 88.9 \\
4 & 34 & Male & 175.6 & 84.8 \\
5 & 37 & Male & 180.3 & 112.9 \\
Mean \pm SD & $34 \pm 4.6$ & & $170.7 \pm 10.7$ & $89.2 \pm 15.9$ \\
\hline
\end{tabular}

$\mathrm{SD}$, standard deviation.

\section{Data analysis}

Descriptive statistics were used to assess data pertaining to $\mathrm{VO}_{2}$ and biomechanical analysis, which were analyzed at 3 different stages. Stage 3 represented the speed at which threshold $\mathrm{VO}_{2}$ occurred during initial and follow-up testing, while stages 1 and 2 represented the two preceding treadmill speeds prior to threshold. Threshold $\mathrm{VO}_{2}$ refers to the point when subjects transitioned from aerobic respiration to anaerobic respiration as determined by volumetric measurements of oxygen and carbon dioxide. For data analysis purposes, treadmill speeds between initial and follow-up testing for the 3 stages remained consistent to allow comparison of initial and final $\mathrm{VO}_{2}$ at each stage.

\section{RESULTS}

\section{Subjects}

Eight subjects volunteered for this program. Two subjects did not complete the program due to absence from the RunSmart sessions and one person was unable to complete the program as a result of a knee injury obtained outside of training. Thus, 5 subjects completed the program. Demographic characteristics are provided in Table 1.

\section{Oxygen consumption}

The mean absolute threshold for $\mathrm{VO}_{2}$ improved from initial to follow-up testing (Tables 2, 3). Table 2 represents the $\mathrm{VO}_{2}$ at each stage during initial and final testing as well as the threshold $\mathrm{VO}_{2}$ at final testing if subjects improved the speed at which they reached threshold values. Mean absolute threshold $\mathrm{VO}_{2}$ at final testing was $3,432.9 \mathrm{~mL} / \mathrm{min}$, improved from $3,144.6 \mathrm{~mL} / \mathrm{min}$ at the time of initial testing; further analysis indicated that 4 of the 5 subjects increased their absolute threshold $\mathrm{VO}_{2}$ (Table 2). Also, at the time of follow-up, the mean threshold $\mathrm{VO}_{2}$ was $91.7 \%$ during stage 3; 3 subjects (1, 3, and 5) improved their threshold $\mathrm{VO}_{2}$ percentage from initial to final testing. This indicates a lower 
Table 2. Oxygen consumption for each of the 3 stages during initial and follow-up testing, as well as the threshold oxygen consumption $\left(\mathrm{VO}_{2}\right)$ at follow-up testing; all subjects except subject 4 improved the speed at which they reached threshold values

\begin{tabular}{|c|c|c|c|c|c|c|c|}
\hline \multirow{2}{*}{ Subject No. } & \multicolumn{3}{|c|}{ Initial $\mathrm{VO}_{2}$ submaximal (mL/min) } & \multicolumn{4}{|c|}{ Follow-up $\mathrm{VO}_{2}$ submaximal (mL/min) } \\
\hline & Stage 1 & Stage 2 & Stage 3 & Stage 1 & Stage 2 & Stage 3 & Threshold \\
\hline 1 & $2,481.2$ & $2,816.0$ & $2,895.3$ & $2,384.0$ & $2,844.0$ & $3,226.0$ & $3,337.0$ \\
\hline 2 & $2,292.3$ & $2,681.3$ & $3,136.1$ & $2,701.4$ & $3,003.4$ & $3,186.0$ & $3,186.0$ \\
\hline 3 & $2,191.1$ & $2,883.2$ & $3,105.3$ & $2,377.0$ & $2,890.6$ & $3,266.5$ & $3,693.8$ \\
\hline 4 & $3,860.1$ & $4,234.6$ & $4,372.9$ & $4,123.5$ & $4,196.4$ & $4,261.9$ & $4,261.9$ \\
\hline 5 & $2,016.5$ & $2,170.0$ & $2,213.3$ & $2,482.9$ & $2,527.4$ & $2,577.0$ & $2,685.6$ \\
\hline Mean \pm SD & $2,568.2 \pm 741.5$ & $2,957.0 \pm 766.0$ & $3,144.6 \pm 780.0$ & $2,813.8 \pm 743.8$ & $3,092.4 \pm 641.9$ & $3,303.5 \pm 605.7$ & $3,432.9 \pm 588.2$ \\
\hline
\end{tabular}

Table 3. Percent of the threshold oxygen consumption reached at each of the three stages of testing

\begin{tabular}{|c|c|c|c|c|c|c|}
\hline \multirow{2}{*}{ Subject No. } & \multicolumn{3}{|c|}{ Initial testing } & \multicolumn{3}{|c|}{ Follow-up testing } \\
\hline & Stage 1 & Stage 2 & Stage 3 & Stage 1 & Stage 2 & Stage 3 \\
\hline 1 & 85.7 & 97.3 & 100 & 71.4 & 85.2 & 74.9 \\
\hline 2 & 73.1 & 85.5 & 100 & 84.8 & 94.3 & 100 \\
\hline 3 & 70.6 & 92.9 & 100 & 64.4 & 78.3 & 88.4 \\
\hline 4 & 88.3 & 96.8 & 100 & 96.8 & 98.5 & 100 \\
\hline 5 & 91.1 & 98.0 & 100 & 92.5 & 94.1 & 95.0 \\
\hline Mean \pm SD & $81.2 \pm 9.3$ & $94.1 \pm 5.2$ & $100 \pm 0$ & $82.0 \pm 13.8$ & $90.1 \pm 8.2$ & $91.7 \pm 10.5$ \\
\hline
\end{tabular}

SD, standard deviation.

Table 4. Maximal angles of ankle dorsiflexion, knee extension, knee flexion and hip flexion during initial and follow-up testing

\begin{tabular}{|c|c|c|c|c|c|c|c|c|}
\hline \multirow{2}{*}{ Subject No. } & \multicolumn{4}{|c|}{ Initial testing } & \multicolumn{4}{|c|}{ Follow-up testing } \\
\hline & Ankle dorsiflexion $\left({ }^{\circ}\right)$ & Knee extension $\left({ }^{\circ}\right)$ & Knee flexion $\left({ }^{\circ}\right)$ & Hip flexion $\left({ }^{\circ}\right)$ & Ankle dorsiflexion $\left({ }^{\circ}\right)$ & Knee extension $\left({ }^{\circ}\right)$ & Knee flexion $\left({ }^{\circ}\right)$ & Hip flexion ( $\left.{ }^{\circ}\right)$ \\
\hline 1 & 10.7 & 173.3 & 105.9 & 32.2 & 2.7 & 163.1 & 111.4 & 42.4 \\
\hline 2 & 9.6 & 170.5 & 93.9 & 31.4 & -15.3 & 169.3 & 114.4 & 41.1 \\
\hline 3 & 7.7 & 177.5 & 107.6 & 26.8 & -12.3 & 168.9 & 105.7 & 34.8 \\
\hline 4 & 7.8 & 174.1 & 93.7 & 27.9 & -4.2 & 170.7 & 103.2 & 38.5 \\
\hline 5 & 10.4 & 171.9 & 89.9 & 29.5 & -5.9 & 164.9 & 105.1 & 32.8 \\
\hline Mean \pm SD & $9.2 \pm 1.4$ & $173.5 \pm 2.6$ & $98.2 \pm 8.0$ & $29.6 \pm 2.3$ & $-7.0 \pm 7.1$ & $167.4 \pm 3.2$ & $108.0 \pm 4.7$ & $37.9 \pm 4.1$ \\
\hline
\end{tabular}

SD, standard deviation.

threshold percentage of $\mathrm{VO}_{2}$ submaximal at the corresponding stage of initial testing, suggesting that subjects required a smaller percentage of their threshold $\mathrm{VO}_{2}$ to run at the same speed during initial testing (Table 3).

\section{Lower extremity biomechanical analysis}

Maximal angles of ankle dorsiflexion, knee extension, knee flexion, and hip flexion during initial and follow-up testing are presented in Table 4. Subjects demonstrated less knee extension at initial contact during the follow-up testing session $\left(167.4^{\circ}\right.$ vs. $\left.173.5^{\circ}\right)$. Less knee extension at initial contact also corresponded to decreased ankle dorsiflexion and midfoot striking. All participants except for subject 3 achieved a greater degree of knee flexion during swing phase; greater knee flexion requires less energy expenditure in order to drive the leg forward for initial contact. Subjects also achieved a greater degree of maximal hip flexion during swing phase, which allows the lower leg to be carried through swing by momentum and positioned in a more optimal position for initial contact.

\section{DISCUSSION}

The purpose of this case series was twofold: (a) to determine if the RunSmart program coincides with improvements in $\mathrm{VO}_{2}$, a variable often associated with better running performance times, and (b) to evaluate the RunSmart program in regard to enhancing 
gait biomechanics. Following completion of the RunSmart program, subjects demonstrated improvements in $\mathrm{VO}_{2}$ and also improved several biomechanical factors related to the lower extremity running gait.

Trends show that runners completing the program displayed decreased ankle dorsiflexion and increased knee extension at initial contact as well as increased hip and knee flexion during swing phase. During the RunSmart training program, runners were instructed to transition to a midfoot strike. To transition from a heel strike to a midfoot strike, runners were taught to land with the shin in a vertical position; runners practiced this landing pattern while walking and progressively increased their speed so that the pattern was incorporated into their running. Runners were also encouraged to increase the amount of knee flexion and hip flexion during swing to maximize running efficiency. In subsequent sessions, training was focused on muscular weakness and range of motion limitations; runners were also assessed each week to ensure that they were effectively incorporating the new foot strike pattern and run form. Therefore, based upon the data in this case series, the RunSmart training program appeared to positively alter the gait biomechanics of the subjects. Furthermore, mean absolute threshold $\mathrm{VO}_{2}$ and mean threshold $\mathrm{VO}_{2}$ percentage improved from initial to follow-up testing. Although there was some intersubject variation for changes in $\mathrm{VO}_{2}$, the results demonstrate a trend for improved $\mathrm{VO}_{2}$ with positive alterations in gait biomechanics following completion of the RunSmart program.

Cavanagh et al. (1977) compared biomechanical variables such as foot strike and shank angle at initial contact and knee and hip flexion during swing phase of gait between elite and good runners. Researchers concluded that elite runners, compared to good runners, exhibited greater knee and hip flexion during swing phase and greater knee extension and decreased ankle dorsiflexion at initial contact; however, the relationship between efficiency and these biomechanical variables were only moderate in strength (Cavanagh et al., 1977). In comparison, the subjects in this case series demonstrated less knee extension and less ankle dorsiflexion at initial contact as well as greater hip and knee flexion during swing phase. These improvements also appeared to correspond with improved $\mathrm{VO}_{2}$, suggesting improved running economy.

A potential explanation for the difference in results between studies is the classification of runners into good and elite status by Cavanagh et al. (1977). Instead of recruiting runners meeting the good or elite qualifications, the subjects in the present case series had limited running experience based on the assumption that less experienced runners would more readily be able to change their running form as well as display greater changes in $\mathrm{VO}_{2}$. Similar to Cavanagh et al. (1977), Williams and Cavanagh (1987) compared 3 groups of runners based on efficiency and found that better runners displayed shank angles further away from vertical indicating greater knee extension moment at initial contact. However, the difference in shank angle between each group of runners was less than 3 degrees and not clinically significant (Williams and Cavanagh, 1987). Runners in the present case series were encouraged to strike the ground with their tibia perpendicular to the running surface. It has been hypothesize that greater knee extension leads to a rear-foot strike pattern at initial contact and creates a braking force at the ankle and knee joint. This braking force is not only detrimental to lower extremity joints but this force also decreases running efficiency by forcing the runner to overcome the negative braking force needed to propel forward. Additionally, in a recent study by Goss and Gross (2013), they concluded that Chi runners, or runners landing with a midfoot or fore-foot strike pattern experienced less negative work around the knee joint thus decreasing the amount of quadriceps work and enhancing efficiency. Runners gain efficiency by decreasing the amount of energy required to create a forward propulsive moment. By manipulating biomechanical variables associated with decreased muscular recruitment and force generation, runners decrease their energy demand thus improving efficiency and improving $\mathrm{VO}_{2}$.

Runners in this case series were encouraged to increase the amount of knee flexion and hip flexion during swing to maximize running efficiency. It has been hypothesize that greater knee flexion during swing phase decreases the moment arm of gravity acting on the lower leg. As a result, knee flexors require less energy to overcome gravity and hip flexors advancing the limb require less force to swing the limb forward. Additionally, greater hip flexion drives the swing leg forward creating a more powerful extension moment in the planted limb due to an increased crossed extension response. Greater extension moment in the plant limb may result in greater forward propulsion and an increase the amount of momentum produced, thus decreasing the amount of muscular energy needed for propulsion.

Limitations in the present study should be considered. The most obvious limitation in the present study is the small sample size $(n=5)$. Given the small sample size which included healthy subjects, the external validity is limited and caution should be used in interpreting the results. Throughout the training period, exercise variables were monitored via patient report. Participants may not have stayed in the designated heart rate zone, completed the proper workout, ran with appropriate form, or performed the 
necessary exercises as instructed. Additionally, the 6-week study period may not have been a substantial amount of time to maximize changes in $\mathrm{VO}_{2}$ or biomechanical factors. Moreover, this time period may not have been long enough for a person to conceptually understand a new running style and physically perform the necessary training regime consistently and accurately.

Based on the results from this case series, the RunSmart training program may have the potential to change a runner's form and improve $\mathrm{VO}_{2}$, thus resulting in improved distance running times. However, this is speculation given the nonexperimental nature of this case series. Future research on this topic should include a greater number of participants in randomized controlled trials with long-term follow-up on injury prevention and running efficiency.

\section{CONFLICT OF INTEREST}

No potential conflict of interest relevant to this article was reported.

\section{REFERENCES}

Anderson T. Biomechanics and running economy. Sports Med 1996;22:76-

89.
Cavagna GA, Saibene FP, Margaria R. Mechanical work in running. J Appl Physiol 1964;19:249-256.

Cavanagh PR, Pollock ML, Landa J. A biomechanical comparison of elite and good distance runners. Ann N Y Acad Sci 1977;301:328-345.

Cavanagh PR, Williams KR. The effect of stride length variation on oxygen uptake during distance running. Med Sci Sports Exerc 1982;14:3035.

Goss DL, Gross MT. A comparison of negative joint work and vertical ground reaction force loading rates in Chi runners and rearfoot-striking runners. J Orthop Sports Phys Ther 2013;43:685-692.

Heise GD, Martin PE. "Leg spring" characteristics and the aerobic demand of running. Med Sci Sports Exerc 1998;30:750-754.

Nummela A, Keränen T, Mikkelsson LO. Factors related to top running speed and economy. Int J Sports Med 2007;28:655-661.

Tartaruga MP, Brisswalter J, Peyré-Tartaruga LA, Avila AO, Alberton CL, Coertjens M, Cadore EL, Tiggemann CL, Silva EM, Kruel LF. The relationship between running economy and biomechanical variables in distance runners. Res Q Exerc Sport 2012;83:367-375.

Wahrlich V, Anjos LA, Going SB, Lohman TG. Validation of the VO2000 calorimeter for measuring resting metabolic rate. Clin Nutr 2006;25: 687-692.

Williams KR, Cavanagh PR. Relationship between distance running mechanics, running economy, and performance. J Appl Physiol (1985) 1987;63:1236-1245. 
Bogulski J, et al. • The RunSmart training program

Appendix. Target heart rate zones, weekly running schedule, and participant daily running log

\begin{tabular}{|c|c|c|c|c|c|c|c|}
\hline \multicolumn{3}{|c|}{ Heart Rate Zones } & Min & Max & & & \\
\hline \multicolumn{3}{|c|}{ Zone 1} & \multicolumn{2}{|c|}{$<75 \%$} & & & \\
\hline \multicolumn{2}{|c|}{ Zone 2} & \multicolumn{2}{|r|}{$75 \%$} & $80 \%$ & & & \\
\hline \multicolumn{2}{|c|}{ Zone 3} & \multicolumn{2}{|r|}{$81 \%$} & $85 \%$ & & & \\
\hline \multicolumn{2}{|c|}{ Zone 4} & \multicolumn{2}{|r|}{$86 \%$} & $90 \%$ & & & \\
\hline \multicolumn{2}{|c|}{ Zone 5} & \multicolumn{2}{|r|}{$91 \%$} & $100 \%$ & & & \\
\hline \multirow{9}{*}{$\begin{array}{l}-1 \\
\text { y } \\
3\end{array}$} & & Run 1 & Run 2 & Run 3 & Run 4 & Run 5 & Total Time \\
\hline & \multicolumn{7}{|c|}{ Target } \\
\hline & Time & 50 & 40 & 55 & 40 & 80 & 265 \\
\hline & Heart Rate Zone & $\begin{array}{l}\text { Warm-up } 10 \text { minutes } \\
\text { easy. Then do } 4 \times 2 \\
\text { minutes. Build to } \\
\text { heart rate zone } 4 \text { ( } 2 \\
\text { minute recoveries). } \\
\text { Relaxed form. }\end{array}$ & Zone 1 - 2 & $\begin{array}{l}\text { Warm up } 10 \text { minutes, } \\
\text { then zone } 1-2 \text { and } \\
\text { then } 10 \text { minutes in } \\
\text { zone } 3 \text { with a } \\
\text { continuous heart rate. } \\
\text { Mostly flat. Remainder } \\
\text { zone } 2 \text {. }\end{array}$ & Zone 1 - 2 & Zone 1 - 2 & \\
\hline & & & & ost Run Data & & & \\
\hline & Time & & & & & & \\
\hline & Miles & & & & & & \\
\hline & Avg Heart Rate & & & & & & \\
\hline & Pace & & & & & & \\
\hline \multirow{9}{*}{$\begin{array}{l}N \\
\text { U } \\
⿱ 亠 䒑 \\
S\end{array}$} & & Run 1 & Run 2 & Run 3 & Run 4 & Run 5 & Total Time \\
\hline & & & & Target & & & \\
\hline & Time & 55 & 45 & 60 & 40 & 90 & 290 \\
\hline & Heart Rate Zone & $\begin{array}{l}\text { Warm-up } 10 \text { minutes } \\
\text { easy. Then do } 4 \times 3 \\
\text { minutes. Build to } \\
\text { heart rate zone } 4 \text { ( } 2 \\
\text { minute recoveries). } \\
\text { Remainder in zone } 1 \text { - } \\
2 \text {. }\end{array}$ & Zone 1 - 2 & $\begin{array}{l}\text { Warm up } 10 \text { minutes, } \\
\text { then zone } 1-2 \text { and } \\
\text { then } 15 \text { minutes in } \\
\text { zone } 3 \text { with a } \\
\text { continuous heart rate. } \\
\text { Mostly flat. Remainder } \\
\text { zone } 2 .\end{array}$ & $\begin{array}{l}\text { Zone } 1 \text { - } 2 \\
\text { r }\end{array}$ & Zone 1 - 2 & \\
\hline & \multicolumn{7}{|c|}{ Post Run Data } \\
\hline & Time & & & & & & \\
\hline & Miles & & & & & & \\
\hline & Avg Heart Rate & & & & & & \\
\hline & Pace & & & & & & \\
\hline \multirow{9}{*}{$\begin{array}{l}m \\
y \\
\dot{d} \\
3\end{array}$} & & Run 1 & Run 2 & Run 3 & Run 4 & Run 5 & Total Time \\
\hline & & & & Target & & & \\
\hline & Time & 60 & 45 & 60 & 45 & 100 & 310 \\
\hline & Heart Rate Zone & $\begin{array}{l}\text { Warm-up } 10 \text { minutes } \\
\text { easy. Then do } 4 \times 4 \\
\text { minutes. Build to } \\
\text { heart rate in zone } 4 \text { ( } 3 \\
\text { minute recoveries). } \\
\text { Remainder in zone } 1 \text { - } \\
2 .\end{array}$ & Zone 1 - 2 & $\begin{array}{l}\text { Warm up } 10 \text { minutes, } \\
\text { then zone } 1-2 \text { and } \\
\text { then } 20 \text { minutes in } \\
\text { zone } 3 \text { with a } \\
\text { continuous heart rate. } \\
\text { Mostly flat. Remainder } \\
\text { zone } 2 \text {. }\end{array}$ & Zone 1 - 2 & Zone 1 - 2 & \\
\hline & \multicolumn{7}{|c|}{ Post Run Data } \\
\hline & Time & & & & & & \\
\hline & Miles & & & & & & \\
\hline & Avg Heart Rate & & & & & & \\
\hline & Pace & & & & & & \\
\hline \multirow{9}{*}{$\begin{array}{l} \pm \\
y \\
\Xi\end{array}$} & & Run 1 & Run 2 & Run 3 & Run 4 & Run 5 & Total Time \\
\hline & & & & Target & Kuाt & & \\
\hline & Time & 40 & 35 & 50 & 35 & 70 & 230 \\
\hline & Heart Rate Zone & $\begin{array}{l}\text { Warm-up } 10 \text { minutes } \\
\text { easy. Then do } 4 \times 2 \\
\text { minutes. Build to } \\
\text { heart rate in zone } 4 \text { ( } 2 \\
\text { minute recoveries). } \\
\text { Remainder in zone } 1 \text { - } \\
2 .\end{array}$ & Zone 1 - 2 & $\begin{array}{l}\text { Warm up } 10 \text { minutes, } \\
\text { then zone } 1-2 \text { and } \\
\text { then } 10 \text { minutes in } \\
\text { zone } 3 \text { with a } \\
\text { continuous heart rate. } \\
\text { Mostly flat. Remainder } \\
\text { zone } 2 \text {. }\end{array}$ & Zone 1 - 2 & Zone 1 - 2 & \\
\hline & \multicolumn{7}{|c|}{ Post Run Data } \\
\hline & Time & & & & & & \\
\hline & Miles & & & & & & \\
\hline & Avg Heart Rate & & & & & & \\
\hline & Pace & & & & & & \\
\hline
\end{tabular}


Appendix. Continued

\begin{tabular}{|c|c|c|c|c|c|c|c|}
\hline \multirow{9}{*}{ 号 } & & Run 1 & Run 2 & Run 3 & Run 4 & Run 5 & Total Time \\
\hline & \multicolumn{7}{|c|}{ Target } \\
\hline & Time & 60 & 50 & 60 & 50 & 110 & 330 \\
\hline & Heart Rate Zone & $\begin{array}{l}\text { Warm-up } 10 \text { minutes } \\
\text { easy. Then do } 4 \times 5 \\
\text { minutes. Build to } \\
\text { heart rate in zone } 4 \text { ( } 3 \\
\text { minute recoveries). } \\
\text { Remainder in zone } 1 \text { - } \\
2 \text {. }\end{array}$ & Zone 1 - 2 & $\begin{array}{l}\text { Warm up } 10 \text { minutes, } \\
\text { then zone } 1-2 \text { and } \\
\text { then } 20 \text { minutes in } \\
\text { zone } 3 \text { with a } \\
\text { continuous heart rate. } \\
\text { Mostly flat. Remainder } \\
\text { zone } 2 \text {. }\end{array}$ & Zone 1 - 2 & Zone 1 - 2 & \\
\hline & \multicolumn{7}{|c|}{ Post Run Data } \\
\hline & Time & & & & & & \\
\hline & Miles & & & & & & \\
\hline & Avg Heart Rate & & & & & & \\
\hline & Pace & & & & & & \\
\hline \multirow{9}{*}{ 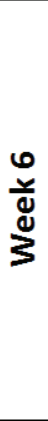 } & & Run 1 & Run 2 & Run 3 & Run 4 & Run 5 & Total Time \\
\hline & & & & Target & & & \\
\hline & Time & 60 & 50 & 60 & 50 & 110 & 330 \\
\hline & Heart Rate Zone & $\begin{array}{l}\text { Warm-up } 10 \text { minutes } \\
\text { easy. Then do } 4 \times 6 \\
\text { minutes. Build to } \\
\text { heart rate in zone } 4 \text { ( } 3 \\
\text { minute recoveries). } \\
\text { Remainder in zone } 1 \text { - } \\
2 .\end{array}$ & Zone 1 - 2 & $\begin{array}{l}\text { Warm up } 10 \text { minutes, } \\
\text { then zone } 1-2 \text { and } \\
\text { then } 30 \text { minutes in } \\
\text { zone } 3 \text { with a } \\
\text { continuous heart rate. } \\
\text { Mostly flat. Remainder } \\
\text { zone } 2 .\end{array}$ & Zone 1 - 2 & Zone 1 - 2 & \\
\hline & \multicolumn{7}{|c|}{ Post Run Data } \\
\hline & Time & & & & & & \\
\hline & Miles & & & & & & \\
\hline & Avg Heart Rate & & & & & & \\
\hline & Pace & & & & & & \\
\hline
\end{tabular}

